\title{
Separate Beds: A History of Indian Hospitals in Canada, 1920s-1980s, by Maureen K. Lux, University of Toronto Press, 2016.
}

\author{
Maureen K. Lux's new work, Separate Beds: A History of Indian Hospitals in
} Canada, 1920s-1980s, is a well researched examination of Indian hospitals on the Canadian prairies in the twentieth century. Previously awarded for her other work on Aboriginal health in Canada, historian Maureen K. Lux, of Brock University, demonstrates her expertise in this field through this extensive examination of a particular type of institution and period in Aboriginal history in Canada. Lux's goal is to focus on material realities in order to more accurately portray all aspects of this experience and she achieves this goal in this expansive, narrative-like historical analysis. In spite of, and perhaps because of, minor limitations in this broad analysis, this work will generate discussions and new avenues for examining the history of Indian hospitals in Canada.

Lux examines Indian hospitals as a place for the intersection of race, medicine, and public policy within the wider context of the changing environment of twentieth-century Canadian healthcare. The main goal of the book is to examine the history of Indian hospitals in Canada as another tool that the federal government utilized to achieve its aims of Aboriginal assimilation, civilizing, and simultaneous isolation. Presented as a thematic study, this new work looks at the rationales for enhanced segregation through Indian hospitals. It examines the associated emphasis on tuberculosis, staffing and operations of the institutions themselves, hospital experiences for the patients and staff, Indian Health Service's (IHS) attempt to shift responsibilities to other bureaucratic organizations, and community resistance. In her own words, this study attempts to show " $[$ how $]$ it became normal and natural to see those narratives [of Aboriginal patients] as separate," from the rest of Canadian health care. ${ }^{1}$

This work should quickly become useful to students and researchers across various historical disciplines including, but not limited to, areas such as Aboriginal

${ }^{1}$ Maureen K. Lux, Separate Beds: A History of Indian Hospitals in Canada, 1920s-1980s (University of Toronto Press, 2016), 18. 
history and medical history in Canada. Gender historians, especially those with an interest in women in medicine, will also benefit from the analysis within Lux's work. Put together as a broad study of an institution over a long period of time, this study captures multiple aspects of this complicated history and covers a lot of information in a concise and well-thought out manner. Lux's work reads like a well-put-together and researched narrative; it is a pleasure to read.

Lux's work contributes to the growing literature on healthcare and Aboriginal peoples in Canadian history. She also works to situate her examination of Indian hospitals within the larger framework of assimilation tools and institutions used by the Canadian government. This element of Lux's work makes it all the more current and necessary to include in the conversation about the Canadian government's relationship with Aboriginal peoples. For instance, the connections she makes to the residential schools are essential to conversations which are developing because of the Truth and Reconciliation Commission of Canada (TRC). While she presents numerous aspects for discussion, Lux does not claim to be presenting a comprehensive analysis of all the Indian hospitals on the Canadian prairies during the twentieth century, of which she states there were twenty-two by 1960. Rather, she focuses on a thematic examination of commonalities between the IHS bureaucracy and their operations within the hospitals.

She begins her study with a story about the opening day of the Charles Camsell Indian Hospital in Edmonton, Alberta. Continuously, Lux returns to the example of the Camsell making it one of, if not the, central hospital in her story. She specifically demonstrates the unique nature of the Camsell because of its close associations with the University of Alberta Hospital and medical school. Lux argues that a large part of the success and longevity of the Camsell was based on its ability to provide subjects for study for the students of the University of Alberta's medical school - subjects with special cases and without the social position to formally question their medical treatment. In Lux's view, the Camsell and its patients had a particular “usefulness.” 2

While this is an important and true connection shared between the University and the Indian hospital in Edmonton, a large aspect of the analysis which

\footnotetext{
${ }^{2}$ Lux, Separate Beds, 13.
} 
is missing is a contextualization of why Edmonton was the centre of northern hospitalization for Aboriginal and Inuit people, and why the University of Alberta's medical school was so central to this story. Lux's work, when focussing on the Camsell in this way, could have drawn upon the aspects and history of the University of Alberta's previous medical school requirement to do service in a northern, isolated community, and the legacy of this requirement in the medical school's culture. ${ }^{3}$ Her focus on one aspect of the historical analysis of the Camsell leaves room to discuss other perspectives and influences which allowed the medical school and the Indian hospital to cooperate in this way, in Edmonton. ${ }^{4}$

Furthermore, Lux's study is limited in its discussion of physician's opinions and experiences in the Indian hospitals. Beyond her attention to the western medical experts who convened and debated the Indian hospitals as an institution in Canada, such as Dr. Percy Moore, she fails to include the general physician's perspective. In this respect, and with specific reference to the knowledge of other wages and situations of other physicians, Lux's study lacks contextualization from the perspective of the doctors within the Indian hospitals. Obviously, not all perspectives can be addressed in a given text but, her work would have benefitted from better acknowledgement of the views of physicians, where possible. For instance, she incorporates a quote from a letter which presents the argument that "many IHS physicians, [were] not aware of their peers' increasingly lucrative incomes in private practice." ${ }^{5}$ This idea appears to be short sighted. Her argument is that physicians simply were not aware of other lucrative opportunities, and therefore were complacent to remain with the Indian Health Service. Though this may be true, in some cases or all, her argument seems over simplified. Therefore, future work may benefit from the inclusion of physician's perspective in a more complete way.

\footnotetext{
${ }^{3}$ For information on this aspect of the University of Alberta's medical school history, see: Elise A. Corbet, Frontiers of Medicine: A History of Medical Education and Research at the University of Alberta (Edmonton: University of Alberta Press, 1990).

${ }^{4}$ Lux focuses on the work of Donna Dryden, Elva Taylor, Rona Beer, Ron Bergman, and Margaret Cogill, The Camsell Mosaic: The Charles Camsell Hospital, 1945-1985 (Edmonton: Charles Camsell History Committee, 1985) but she does not provide information on the history of the University of Alberta's medical school as important context to her argument.

${ }^{5}$ Lux, Separate Beds, 57.
} 
However, Lux's work presents greater strengths in research and argument than any debatable limitations. Her study establishes an important part of the story of Indian hospitals by revealing evidence that the Aboriginal leaders in the prairie provinces welcomed the institutions and saw a way they could make use of the western medicine provided within the institutions alongside their own medical practices and traditions. This perspective is not widely acknowledged in previous works and as such makes Lux's study all the more valuable for its ability to reveal various perspectives and initiate discussion. Another renewed point of discussion in Lux's work surrounds the issue of employing Aboriginal people to work in the Indian hospitals. This was, Lux claims, the second central reason for the institutions, however, she points out that in reality this was never fully carried through as an objective. Her analysis of Aboriginal workers is compelling, will generate discussion, and is of particular interest to those interested in looking at women in healthcare, since most of the Aboriginal people who were hired to work in the hospitals were women.

Yet another strength of her work appears in every chapter when, alongside background information, Lux provides her readers with specific stories, individual recollections, and names which her readers can connect with on a different level. This interplay between historical information and personal stories adds to the structure of her study and enhances its narrative-like set up, making for an compelling read. Lux's study contains quotes from patient narratives, some based on her own interviews and others from recent works within the field. This part of her work in particular allows for readers of any level to acknowledge the people behind this history. This is one of the great strengths of her work. She allows for some of the stories to speak for themselves and provides her readers with the information needed to make their own conclusions.

Finally, Lux completes her study with a more in depth look at how healthcare for Aboriginal people came to be seen by Aboriginal people and other Canadians as a federal responsibility. This, she claims, was based mainly off of the medicine chest clause in Treaty Six. Lux's study could have benefitted here from elaborating on what a medicine chest was understood to be at the time of the signing of Treaty Six and the difference in this understanding among the various 
groups which signed Treaty Six - though she does address the definition of a medicine chest briefly throughout her chapters.

Limitations aside, for such a broad analysis, Lux's study is very well contextualized with respect to political, social, and economic aspects. Medical aspects are well explained for a study which does not emphasise the scientific history behind the medicine being used in Indian hospitals. Gender issues are evident, though not specifically the concern of this study. The silences which appear will only generate more discussion, and do not take away from the validity or importance of this study as a whole. Each chapter could be read on its own, making this a great book for a seminar class. Separate Beds: A History of Indian Hospitals in Canada, 1920s-1980s achieves its goal of "[complicating] our understandings of twentieth-century healthcare in Canada," by generating room for discussion and the continuation of this topic of historical study in various directions. ${ }^{6}$ This is truly a valuable study of Indian hospitals as a Canadian institution in the twentieth century.

\section{LETITIA JOHNSON}

University of Alberta

${ }^{6}$ Lux, Separate Beds, 191. 